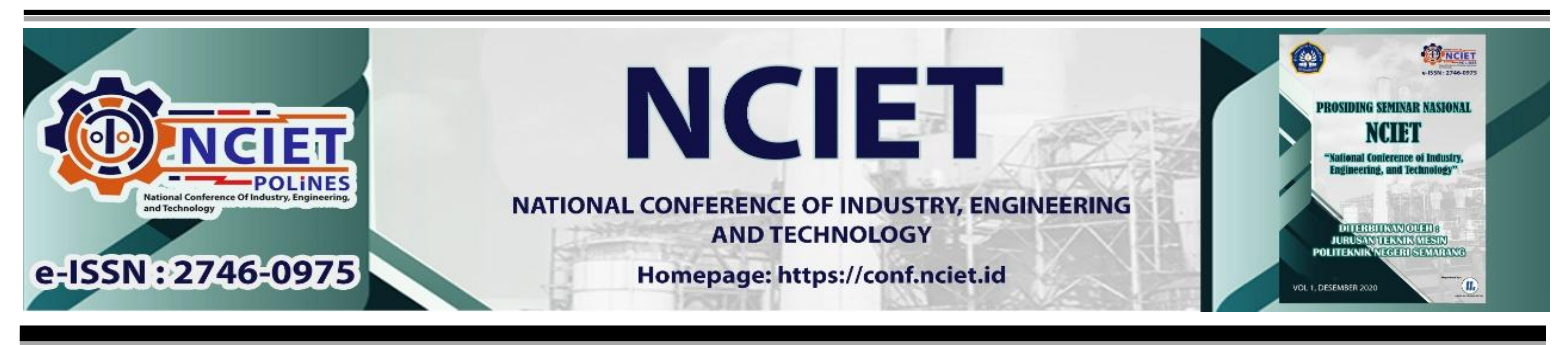

Prosiding Seminar Nasional NCIET Vol.1 (2020) B207-B217

$1^{\text {st }}$ National Conference of Industry, Engineering and Technology 2020,

Semarang, Indonesia.

\title{
RANCANGAN SPIRAL WATER WALL PADA PLTU SUPERCRITICAL KAPASITAS 660 MW
}

\author{
Zefa Fahriza Adriansyah*, Ika Yuliyani \\ Jurusan Teknik Konversi Energi, Politeknik Negeri Bandung \\ Jl. Gegerkalong Hilir, Ds. Ciwaruga Kecamatan Parongpong Kabupaten Bandung Barat, \\ 40012 \\ *E-mail: zefafahriza25@gmail.com
}

\begin{abstract}
Abstrak
Water wall merupakan komponen yang berada didekat ruang bakar boiler dan berfungsi sebagai tempat terjadinya proses perpindahan panas secara radiasi antara gas panas hasil pembakaran dengan fluida kerja yang digunakan pada boiler. Jenis water wall yang paling banyak digunakan pada teknologi supercritical boiler salah satunya yaitu jenis spiral water wall karena mampu menghasilkan perpindahan panas secara lateral pada seluruh dinding pipa. Rancangan water wall yang dibuat pada pembangkit listrik tenaga uap kapasitas 660 MW menggunakan beberapa metode, yaitu diantaranya software basic design, perhitungan secara teoritis dan computer-aided design. Hasil rancangan diperoleh volume furnace water wall sebesar 21.220,24 $\mathrm{m}^{3}$, tinggi furnace water wall sebesar $58 \mathrm{~m}$, lebar furnace water wall sebesar $21,45 \mathrm{~m}$, dan kemiringan spiral water wall sebesar $18^{\circ}$. Besarnya energi kalor yang diserap water wall adalah 598.235,3 $\mathrm{kW}$ yang dapat mengubah fasa fluida kerja (air) menjadi supercritical fluid. Kenaikan nilai temperatur pada pipa water wall terjadi sangat signifikan, sehingga terjadi perubahan fluida kerja berupa fasa cair (air) menjadi fasa uap (supercritical fluid), sesuai dengan siklus rankine pada diagram T-s kondisi supercritical. Temperatur fluida meningkat mulai dari $343,5^{\circ} \mathrm{C}$ menjadi $411,1^{\circ} \mathrm{C}$, yaitu diatas titik kritis air dengan tekanan kritis sebesar 22,1 $M P a$ dan temperature kritis sebesar $374{ }^{\circ} \mathrm{C}$.
\end{abstract}

Kata Kunci: perancangan; spiral water wall; supercritical boiler; PLTU kapasitas 660 MW

\section{PENDAHULUAN}

Pembangkit listrik tenaga uap (PLTU) merupakan salah satu jenis pembangkit listrik yang memanfaatkan energi kimia berupa gas hasil pembakaran untuk membangkitkan energi listrik menggunakan media air sebagai fluida kerja. Pengembangan siklus rankine menghasilkan teknologi baru pada pembangkit listrik tenaga uap. Teknologi yang sudah berkembang diantaranya subcritical boiler, supercritical boiler, ultra-supercritical boiler, dan subcritical fluidized bed (MITs, 2007).

Supercritical boiler merupakan salah satu teknologi pembangkit listrik tenaga uap yang memiliki prinsip serta keunggulan yang berbeda dibandingkan dengan teknologi 
subcritical boiler. Menurut MIT Study (2007) dalam bukunya yang berjudul The Future of Coal, nilai efisiensi siklus pada PLTU subcritical sebesar 33-37\%, sedangkan nilai efisiensi siklus pada PLTU supercritical sebesar 37-40\%. Perbedaan utama antara teknologi supercritical boiler dan subcritical boiler yaitu terletak pada operasi kerja fluida, yang di analisis melalui siklus rankine. Pada supercritical boiler, fluida kerja berada di atas titik kritis (critical point) dengan tekanan operasi mencapai 240 bar yang disebut sebagai "Supercritical Fluid" (Rayaprolu, 2009). Berdasarkan siklus rankine pada teknologi superkritikal, proses perubahan fasa cair menjadi fasa uap yang berubah secara drastis, terjadi pada komponen utama boiler yaitu pada water wall.

Water wall merupakan komponen yang memiliki peranan penting dalam proses perubahan fluida kerja dari fasa cair menjadi uap kering. Water Wall harus mampu beroperasi pada tekanan dan temperatur yang tinggi agar mampu mengoptimalkan proses perubahan fluida kerja cair menjadi supercritical fluid. Jenis water wall yang pada umumnya digunakan yaitu vertical water wall, spiral water wall, dan benson vertical water wall tergantung kebutuhannya.

Spiral water wall merupakan jenis water wall yang umumnya digunakan pada teknologi supercrtitical boiler, karena memiliki keunggulan dibandingkan dengan jenis water wall lainnya. Salah satu keunggulannya yaitu dapat meningkatkan penyerapan panas lateral dan memiliki massa aliran yang besar (Kenneth, 2006).

Tujuan dari penilitian yang dilakukan yaitu untuk menentukan jenis material yang digunakan spiral water wall, memperoleh dan menganalisis hasil rancangan spiral water wall.

\section{METODE PENELITIAN}

Metodologi penelitian rancangan spiral water wall dengan distribusi panas dan aliran dapat dilakukan dengan tahapan-tahapan berikut ini: 


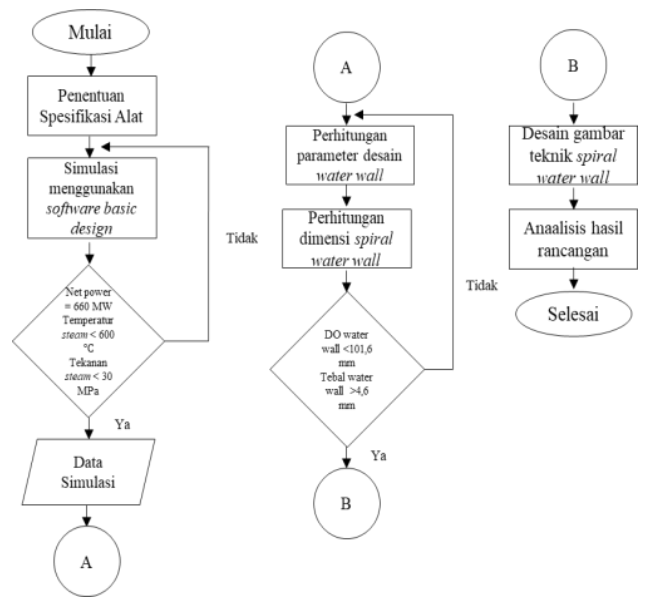

Gambar 1. Diagram alir penelitian

\section{- Pembuatan simulasi basic design untuk memperoleh parameter perhitungan}

Menentukan data sekunder berupa data spesifikasi untuk digunakan sebagai parameter input simulasi yang dilakukan pada software basic design. Simulasi pada software basic design bertujuan untuk mencari parameter yang dibutuhkan pada proses perhitungan. Standar keberhasilan proses simulasi basic design diantaranya kapasitas daya yang dihasilkan (net power) harus mencapai sebesar $660 \mathrm{MW}$, temperatur uap sebesar $<600^{\circ} \mathrm{C}$, dan tekanan uap sebesar <30 MPa. Standar keberhasilan yang digunakan yaitu parameter standar yang digunakan pada pembangkit listrik tenaga uap dengan kapasitas $660 \mathrm{MW}$.

Tabel 1. Data Input Simulasi Basic Design

\begin{tabular}{|c|c|c|}
\hline Data Input & Jumlah & Satuan \\
\hline Conventional Boiler & 1 & Unit \\
\hline $\begin{array}{l}\text { Power Output (net } \\
\text { power) }\end{array}$ & 660 & MW \\
\hline Temperatur ambient & 27 & ${ }^{\circ} \mathrm{C}$ \\
\hline Frekuensi generator & 50 & $\mathrm{~Hz}$ \\
\hline Altitude & 10 & $\mathrm{~m}$ \\
\hline $\begin{array}{l}\text { Temperatur air make } \\
\text { up }\end{array}$ & 25 & $\begin{array}{l}{ }^{\circ} \mathrm{C} \\
\%\end{array}$ \\
\hline $\begin{array}{l}\text { Temperatur air } \\
\text { pendingin }\end{array}$ & 25 & ${ }^{\circ} \mathrm{C}$ \\
\hline $\begin{array}{l}\text { Daya pemakaian } \\
\text { sendiri }\end{array}$ & 5,8 & Bar \\
\hline $\begin{array}{c}\text { Temperatur steam } \\
\text { masuk HPT }\end{array}$ & 573 & ${ }^{\circ} \mathrm{C}$ \\
\hline $\begin{array}{l}\text { Tekanan steam } \\
\text { masuk HPT }\end{array}$ & 258 & Bar \\
\hline $\begin{array}{l}\text { Temperatur steam } \\
\text { masuk IPT }\end{array}$ & 567 & ${ }^{\circ} \mathrm{C}$ \\
\hline $\begin{array}{l}\text { Tekanan steam } \\
\text { masuk IPT }\end{array}$ & 42 & Bar \\
\hline Efisiensi generator & 98,8 & $\%$ \\
\hline
\end{tabular}




\section{- Proses perhitungan secara teoritis untuk memperoleh parameter rancangan}

Tahap awal dalam melakukan proses perhitungan yaitu dengan menentukan ukuran dan jenis material pipa spiral water wall yang akan digunakan. Standar yang digunakan untuk menentukan ukuran pipa water wall yaitu ASTM A213 Tubing Standard Spesification (ASME SA213). Standar ukuran pipa pada ASME 213 yang digunakan dalam rancangan spiral water wall yaitu diameter outlet water tube sebesar $<101,6 \mathrm{~mm}$ dengan tebal water tube sebesar $>4,6 \mathrm{~mm}$. Berikut adalah perhitungan parameter rancangan spiral water wall: Laju Kalor Pada Furnance Water Wall

Proses pembakaran pada ruang bakar terjadi perpindahan panas diantara gas hasil pembakaran terhadap pipa-pipa yang menempel pada dinding ruang bakar (water wall). Perpindahan kalor yang terjadi secara radiasi. Kalor yang dapat diserap oleh furnance water wall dapat dihitung dengan (Moran M. J., Shapiro, Boettner, \& Bailey, 2011):

$$
Q_{w w}=\dot{\mathrm{m}}_{\text {water }} \times(h e-h i)
$$

Dimana :

$Q_{w w} \quad$ : kalor yang diserap water wall $(\mathrm{kW})$

$\dot{\mathrm{m}}_{\text {water: }}$ laju alir massa air $(\mathrm{kg} / \mathrm{s})$

he : entalphy uap yang keluar water wall $(\mathrm{kJ} / \mathrm{kg})$

hi : entalphy uap yang masuk water wall $(\mathrm{kJ} / \mathrm{kg})$

Kalor yang dihasilkan bahan bakar dapat dihitung menggunakan persamaan berikut:

$$
Q_{b b}=\dot{\mathrm{m}}_{b b} \times L H V
$$

Dimana:

$Q_{b b} \quad$ : kalor yang dihasilkan bahan bakar $(\mathrm{kW})$

$\dot{\mathrm{m}}_{b b} \quad$ : laju alir massa bahan bakar $(\mathrm{kJ} / \mathrm{kg})$

$L H V$ : nilai kalor rendah bahan bakar $(\mathrm{kJ} / \mathrm{kg})$

Laju perpindahan panas di furnance water wall adalah penjumlahan dari kalor yang diserap water wall dengan rugi-rugi panas yang terjadi. Maka laju perpindahan panas di furnance water wall dapat dihitung melalui persamaan:

$$
Q r b=Q_{\text {waterwall }}+Q_{\text {rugi total }}
$$

Dimana :

Qrb : Laju perpindahan kalor pada water wall $(\mathrm{kW})$

Temperatur Flue Gas Meninggalkan Water Wall

Perpindahan Kalor Secara Radiasi Pada Water Wall 
Gas hasil pembakaran yang dihasilkan akan melewati pipa yang tersusun mengelilingi boiler, disebut dengan water wall. Pipa tersebut berfungsi sebagai tempat mengalirnya fluida kerja dan untuk mengontrol laju perpindahan kalor secara radiasi. Persamaan untuk menghitung laju perpindahan kalor secara radiasi pada permukaan water wall adalah:

$$
Q_{\text {radiasi }}=U \times A \times F \times(L M T D) \text {. }
$$

Dimana:

$$
\begin{array}{ll}
Q_{\text {radiasi }} & \text { : energi kalor }(\mathrm{kJ} / \mathrm{s}) \\
U & : \text { koefisien perpindahan kalor }\left(\mathrm{kJ} / \mathrm{s} \mathrm{m}^{2}{ }^{\circ} \mathrm{C}\right) \\
A & : \text { luas permukaan perpindahan kalor }\left(\mathrm{m}^{2}\right) \\
F & : \text { faktor koreksi } \\
\text { LMTD } & : \text { log mean temperature different, gasdan saturated water }\left({ }^{\circ} \mathrm{C}\right) \\
\dot{\mathrm{m} g} & : \text { laju alir gas }(\mathrm{kg} / \mathrm{s}) \\
\Delta T g & : \text { selisih temperatur gas masuk dan } \operatorname{keluar}\left({ }^{\circ} \mathrm{C}\right) \\
T 1 & : \text { temperatur gas masuk water wall }\left({ }^{\circ} \mathrm{C}\right) \\
T 2 & : \text { temperatur gas keluar water wall }\left({ }^{\circ} \mathrm{C}\right)
\end{array}
$$

Perpindahan panas yang terjadi pada water wall merupakan perpindahan panas secara radiasi, baik radiasi antara gas hasil pembakaran atau dengan radiasi antar pipa. Log mean temperature difference yang digunakan untuk rancangan water wall dapat diketahui dengan menggunakan persamaan:

$$
L M T D=\frac{T 1-T 2}{\ln \frac{T 1-T / s}{T 2-T / s}}
$$

Dimana:

$T_{1} \quad$ : temperatur gas masuk water wall $\left({ }^{\circ} \mathrm{C}\right)$

$T_{2}$ : temperatur gas keluar water wall $\left({ }^{\circ} \mathrm{C}\right)$

$T^{\prime}{ }_{S} \quad$ : temperatur saturasi air boiler $\left({ }^{\circ} \mathrm{C}\right)$

Perpindahan kalor pada water wall terjadi secara radiasi. Perpindahan panas secara radiasi pada furnace dihitung menggunakan factor efektivitas heat flux yang diperoleh dari hubungan flue gas dengan screen surface emissivities pada grafik. Temperature differential dihitung dari selisih temperatur gas keluar furnace dengan temperatur pipa yang diasumsikan sama nilai nya dengan temperatur saturasi. Menghitung heat flux sesuai dengan hukum Stefan-boltzman menggunakan persamaan:

$$
q^{\prime \prime}=\sigma \times F \times\left(T 1^{4}-T^{\prime} s^{4}\right)
$$


Dimana:

$q^{\prime \prime} \quad$ : heat flux $\left(\mathrm{W} / \mathrm{m}^{2}\right)$

$\sigma \quad$ :konstanta Stefan-boltzman

F : faktor efektivitas heat flux

T1 : temperatur gas keluar furnance $\left({ }^{\circ} \mathrm{C}\right)$

$T^{\prime} S \quad$ : temperatur saturasi gas $\left({ }^{\circ} \mathrm{C}\right)$

Gas film temperatur merupakan perkiraan suhu fluida didalam batasan konveksi. Perkiraan suhu tersebut dihitung sebagai rata-rata dari suhu permukaan dinding pipa dengan suhu aliran fluida. Persamaan untuk menghitung gas film temperatur

$$
T f=T^{\prime} s+\left(\frac{L M T D}{2}\right) \text {. }
$$

Dimana:

$T^{\prime} S \quad$ : temperatur saturasi air boiler $\left({ }^{\circ} \mathrm{C}\right)$

LMTD : log mean temperature difference $\left({ }^{\circ} \mathrm{C}\right)$

Persamaan untuk menghitung gas Reynolds number

$$
R e=\text { Kre.Ge. }
$$

Dimana:

Kre : gas properties factor $\left(\mathrm{s} \mathrm{m}^{2} / \mathrm{kg}\right)$

Ge : gas mass flux $\left(\mathrm{kg} / \mathrm{s} \mathrm{m}^{2}\right)$

Koefisien perpindahan panas konveksi gas film

$$
h^{\prime} c g=h^{\prime} c . F p p . F a . F d \text {. }
$$

Dimana:

$h^{\prime} \mathrm{C} \quad$ : basic convection cross flow geometry and velocity factor $\left(\mathrm{W} / \mathrm{m}^{2}{ }^{\circ} \mathrm{C}\right)$

Fpp : physical properties factor

$\mathrm{Fa}$ : arrangement factor

Fd : heat transfer depth factor

Koefisien perpindahan radiasi gas

$$
h r g=h^{\prime} r . K . F s
$$

Dimana:

$h^{\prime} r \quad$ : basic radiation heat transfer coefficient $\left(\mathrm{W} / \mathrm{m}^{2}{ }^{\circ} \mathrm{C}\right)$

$K \quad$ : faktor bahan bakar

Fs : faktor efektivitas perpindahan panas radiasi 
Gabungan koefisien perpindahan panas

$$
h g=h c g+h r g \text {. }
$$

Dimana:

$h c g$ : koefisien perpindahan panas konveksi gas film $\left(\mathrm{W} / \mathrm{m}^{2}{ }^{\circ} \mathrm{C}\right)$

$h r g \quad$ : koefisien perpindahan panas radiasi gas $\left(\mathrm{W} / \mathrm{m}^{2 \circ} \mathrm{C}\right)$

\section{Derajat Kemiringan Spiral Water Wall}

Proses perancangan dimensi spiral water wall, dapat dihitung derajat kemiringan spiral water wall dengan menggunakan persamaan berikut:

$$
\operatorname{Sin} \alpha h=\frac{p t}{p t h}=\frac{k p d_{1}}{\frac{4 l}{n}}=\frac{k p d_{1} W m m}{4 l \frac{d_{1}^{2} \pi}{4} W^{\prime \prime}}=\frac{W k p}{W^{\prime \prime} \pi l d_{1}} \ldots
$$

Dimana:

Sin $\alpha h:$ derajat kemiringan spiral water wall

kp : konstanta pitch water wall

$d_{1} \quad$ : diameter water tube

W : feed water flow $(\mathrm{kg} / \mathrm{s})$

$W^{\prime \prime} \quad$ : minimum mass flux $\left(\mathrm{kg} / \mathrm{s} . \mathrm{m}^{2}\right)$

$l \quad:$ lebar water wall $(\mathrm{m})$

Dimensi Spiral Water Wall

Perancangan dimensi spiral water wall dapat ditentukan dengan mengetahui volume heat release plate dan mengasumsikan lebar water wall yang dirancang. Berikut adalah persamaannya:

1. Volume spiral water wall

$$
V_{w w}=\frac{Q b b}{V f}
$$

2. Ketinggian spiral water wall

$$
h=8 . l . \operatorname{Sin} \alpha h
$$

Dimana:

$h \quad$ : Tinggi spiral water wall $(\mathrm{m})$

$l \quad$ : Lebar spiral water wall (m)

Sin $\alpha h$ : Derajat kemiringan spiral water wall 


\section{HASIL DAN PEMBAHASAN}

Data yang diperoleh dari hasil simulasi mencakup power plant summary, steam cycle, boiler, cooling system. Data yang diperlukan dalam proses perancangan spiral water wall ini adalah data pada furnace boiler, fuel dan pulverizer.

Tabel 2. Hasil Simulasi Software Basic Design

\begin{tabular}{ccc}
\hline Data Input & Nilai & Satuan \\
\hline Mass flow air & 591.2 & $\mathrm{~kg} / \mathrm{s}$ \\
Entalpy uap keluar water wall & 2583.7 & $\mathrm{~kJ} / \mathrm{kg}$ \\
Entalpy uap masuk water wall & 1571.8 & $\mathrm{~kJ} / \mathrm{kg}$ \\
Temperatur inlet water wall & 343.5 & ${ }^{\circ} \mathrm{C}$ \\
Temperatur outlet water wall & 411.1 & ${ }^{\circ} \mathrm{C}$ \\
Tekanan inlet water wall & & \\
Tekanan outlet water wall & 289.1 & $\mathrm{Bar}$ \\
Temperatur gas keluar furnace & 273.9 & $\mathrm{Bar}$ \\
Temperatur saturasi air & 1121.9 & ${ }^{\circ} \mathrm{C}$ \\
LHV bahan bakar & 343.5 & ${ }^{\circ} \mathrm{C}$ \\
Mass flow bahan bakar & 15244 & $\mathrm{~kJ} / \mathrm{kg}$ \\
Mass flow gas & 107.8 & $\mathrm{~kg} / \mathrm{s}$ \\
Gas mass flux & 850.7 & $\mathrm{~kg} / \mathrm{s}$ \\
Volumetric heat release & 2.671 & $\mathrm{~kg}^{2} \mathrm{~s} \mathrm{~m}$ \\
\hline
\end{tabular}

Proses perhitungan dilakukan dengan pendekatan secara teoritis. Proses perhitungan menghasilkan parameter rancangan dan nilai termodinamika pada spiral water wall.

Tabel 3. Data Hasil Perhitungan

\begin{tabular}{lll}
\hline Hasil perhitungan & Nilai & Satuan \\
\hline Kalor yang diserap water wall & $598.235,3$ & $\mathrm{~kW}$ \\
Kalor yang dihasilkan bahan bakar & $1.643 .303,2$ & $\mathrm{~kW}$ \\
Laju perpindahan panas water wall & $696.833,47$ & $\mathrm{~kW}$ \\
Temperatur flue gas & $1.100,87$ & ${ }^{\circ} \mathrm{C}$ \\
Log Mean Temperature Difference & 767,83 & ${ }^{\circ} \mathrm{C}$ \\
Heat flux & $26.712,42$ & $\mathrm{~W} / \mathrm{m}^{2}$ \\
Minimum gas free flow rate & 318,49 & $\mathrm{~m}^{2}$ \\
Gas film temperature & 727,42 & ${ }^{\circ} \mathrm{C}$ \\
Gas Reynold Number & 4.106 & \\
Koefisien perpindahan panas konveksi & 42 & $\mathrm{~W} / \mathrm{m}^{2}{ }^{\circ} \mathrm{C}$ \\
Koefisien perpindahan panas radiasi & 12,59 & $\mathrm{~W} / \mathrm{m}^{2}{ }^{\circ} \mathrm{C}$ \\
Koefisien perpindahan panas total & 54,59 & $\mathrm{~W} / \mathrm{m}^{2}{ }^{\circ} \mathrm{C}$ \\
Luas perpindahan panas water wall & $39.204,34$ & $\mathrm{~m}^{2}$
\end{tabular}

Sumber: Data primer yang diolah, Tahun 2019 
Tabel 4. Dimensi spiral water wall

\begin{tabular}{lll}
\hline Parameter & Nilai & Satuan \\
\hline Derajat kemiringan water wall & 18,7 & $\circ$ \\
Lebar spiral water wall & 21,45 & $\mathrm{~m}$ \\
Volume spiral water wall & $21.220,24$ & $\mathrm{~m}^{3}$ \\
Tinggi spiral water wall & 58 & $\mathrm{~m}$ \\
Diameter outlet pipa water wall & 38 & $\mathrm{~mm}$ \\
Ketebalan pipa water wall & 7.3 & $\mathrm{~mm}$ \\
\hline
\end{tabular}

Analisis termodinamika fluida kerja pada water wall

Dari data simulasi diperoleh nilai temperatur inlet water wall sebesar $343,5^{\circ} \mathrm{C}$ dan temperatur outlet water wall sebesar $411,1^{\circ} \mathrm{C}$ pada tekanan konstan (kondisi ideal), yaitu sebesar 28,91 MPa atau 289,1 bar. Untuk area fluida kerja pada water wall ditunjukan oleh garis yang berwarna kuning yang merupakan area kerja dari supercritical fluid. Area kerja spiral water wall telah melampaui nilai titik kritis air, dengan tekanan kritis air sebesar 22,1 MPa dan temperatur kritis air sebesar $374{ }^{\circ} \mathrm{C}$. Pada diagram T-s tersebut letak titik kritis air berada di puncak kubah uap pada area berwana ungu.

Dari hasil software tersebut diperoleh bahwa spiral water wall yang dirancang bekerja pada daerah diatas titik kritis dari fluida air sehingga dapat diaplikasikan untuk teknologi supercritical boiler pada PLTU dengan kapasitas 1x660 MW.

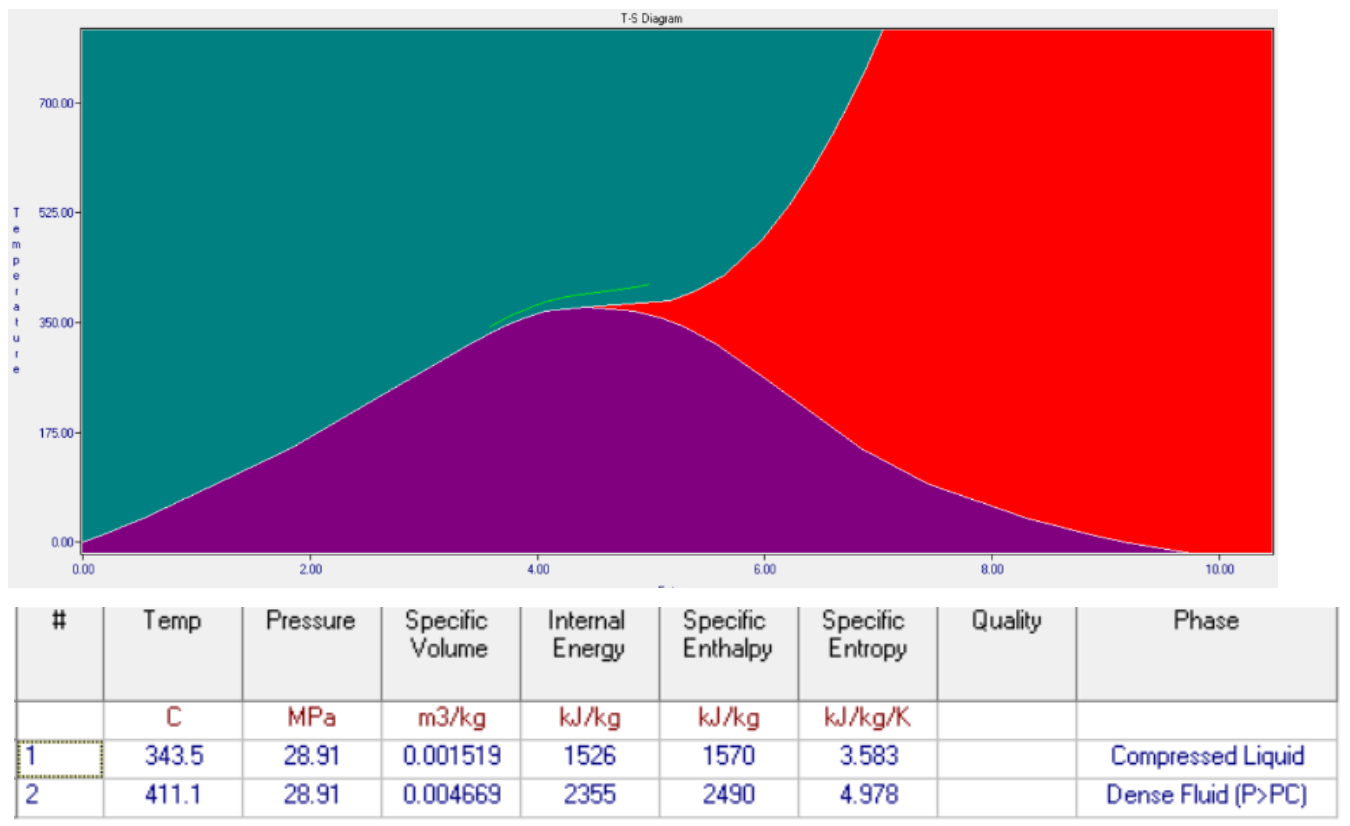

Gambar 2. Termodinamika fluida kerja pada spiral water wall 
Pemilihan jenis dan ukuran material pipa spiral water wall

Kode SA213 merupakan spesifikasi standar ASME yang digunakan untuk rancangan boiler, superheater, dan pipa heat exchanger menggunakan material ferritic, dan alloy steel boiler. Lalu kode T12 menunjukkan grade atau tingkatan heat treatment pada material, dengan tipe heat treatment isothermal, temperatur tempering mulai dari $650{ }^{\circ} \mathrm{C}$ sampai $730{ }^{\circ} \mathrm{C} . \mathrm{T} 12$ dengan jenis material Alloy Steel.

Kemudian dari standar ASME SA213 T12, dapat diperoleh ukuran pipa dengan diameter luar sebesar $38 \mathrm{~mm}$ (1,5 in) dan tebal pipa sebesar 7,3 $\mathrm{mm}$ dengan jenis pipa yaitu bare/smooth tube. Ukuran pipa untuk rancangan spiral water wall dipilih sesuai dengan ukuran pipa yang dicantumkan didalam manual book, dikarenakan kondisi ukuran pipa sudah terbukti (proven).

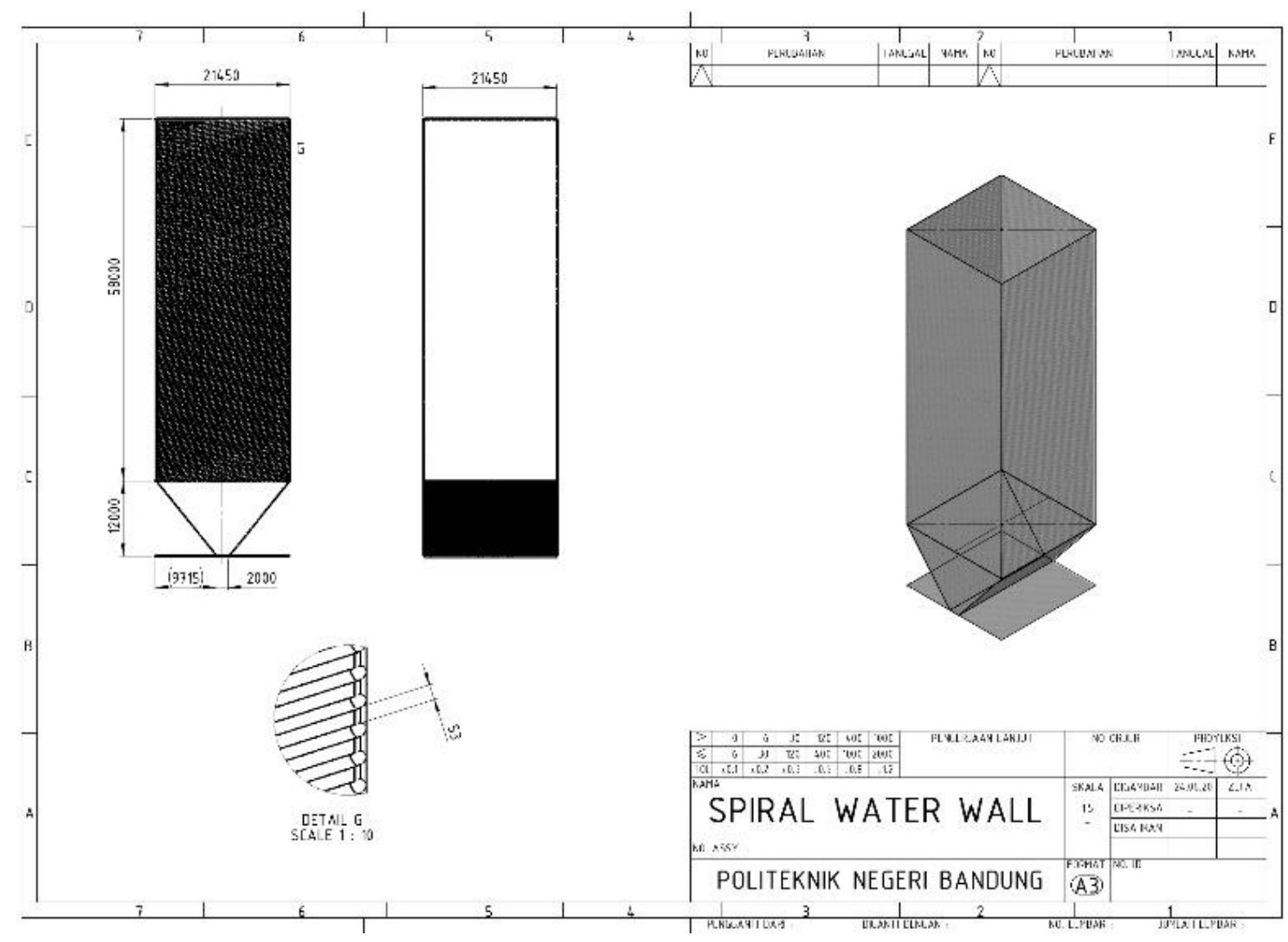

Gambar 3. Hasil rancangan spiral water wall

\section{KESIMPULAN}

Berdasarkan proses perhitungan dan analisis yang telah dilakukan, maka dapat diperoleh kesimpulan jenis material yang digunakan pipa spiral water wall yaitu Alloy Steel. Kemudian ukuran pipa water wall dengan diameter luar sebesar $38 \mathrm{~mm}$ (1,5 in) dan 
tebal pipa sebesar 7,3 mm dengan jenis pipa yaitu bare/smooth tube, sesuai standar ASME SA213 T12 untuk penggunaan pipa penukar panas (heat exchanger).

Hasil simulasi basic design merupakan parameter dasar yang digunakan untuk proses perhitungan. Perhitungan dilakukan dengan pendekatan teoritis dan menghasilkan dimensi spiral water wall. Hasil rancangan diperoleh volume furnace water wall sebesar 21.220,24 $\mathrm{m}^{3}$, tinggi furnace water wall sebesar $58 \mathrm{~m}$, lebar furnace water wall sebesar 21,45 $\mathrm{m}$, dan kemiringan spiral water wall sebesar $18^{\circ}$. Besarnya energi kalor yang diserap water wall adalah 598.235,3 $\mathrm{kW}$ yang dapat mengubah fasa fluida kerja (air) menjadi supercritical fluid. Kenaikan nilai temperatur pada pipa spiral water wall terjadi sangat signifikan, sehingga terjadi perubahan fluida kerja berupa fasa cair (liquid) menjadi fasa uap (supercritical fluid), sesuai dengan siklus rankine pada diagram T-s kondisi supercritical. Temperatur fluida meningkat mulai dari $343,5^{\circ} \mathrm{C}$ menjadi $411,1^{\circ} \mathrm{C}$, yaitu diatas titik kritis air dengan tekanan kritis air sebesar sebesar 22,1 MPa dan temperatur kritis air sebesar $374{ }^{\circ} \mathrm{C}$.

\section{DAFTAR PUSTAKA}

Kitto, J.B., \& Stultz, S.C (2005). Steam its generation and use. Ohio, USA: The Babcock and Wilcox Company.

Gunara Muhamad (2017). Potensi Batu Bara Sebagai Sumber Energi Alternatif Untuk Pengembangan Industri Logam. Jakarta Timur : Seminar Nasional Teknoka. - Vol. II.

MITs (2007). The Future of Coal. United States: Massachusetts Institute of Technology,

Rayaprolu K (2009). Boiler for Power and Process. New York : CRC Press.

Cahyadi Dr. dan budianto Dwika (2015). PLTU Batu Bara Superkritikal Yang Efisien. Tangerang: Balai Besar Teknologi Energi.Vol. Satu.

Wieslaw Zima \& Artur Cebula (2010). Modelling of heat and flow phenomena occuring in waterwall tubes of boilers for supercritical steam parameters. Krakow: Department of Thermal Power Engineering. Vol. 31.

Kenjiro Y.K \& Hiroshi (2013). Design Technology for Supercritical Sliding Pressure Operation Vertical Water Wall Boilers. Japan : Mitsubishi Heavy Industries Technical Review.Vol. 50. 